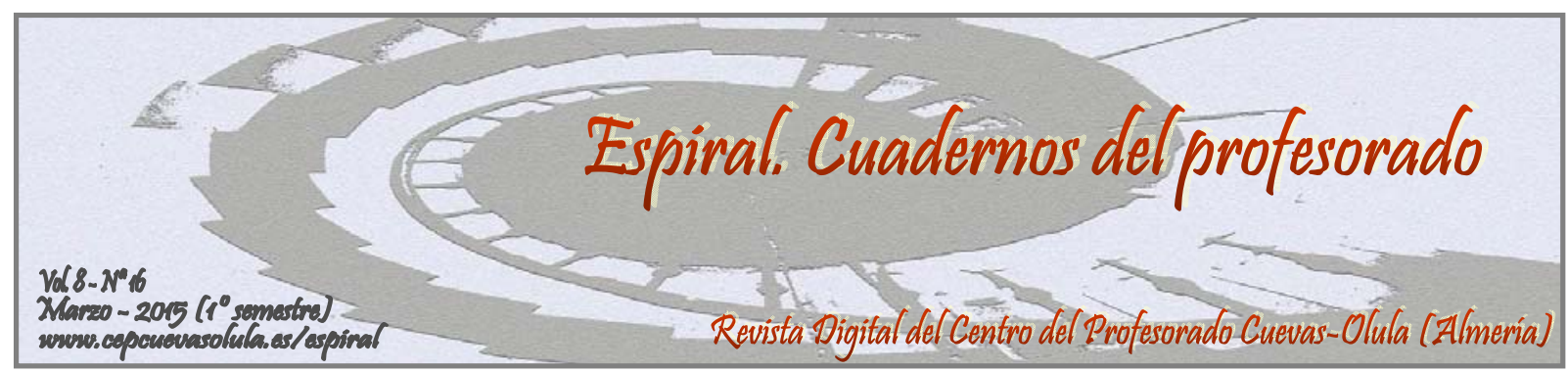

\title{
LA LECTURA DE OBRAS COMPLETAS EN EL AULA DE ESPAÑOL COMO LENGUA EXTRANJERA: AURA, DE CARLOS FUENTES
}

\author{
THE READING OF COMPLETE WORKS IN THE SPANISH AS A FOREIGN \\ LANGUAGE CLASSROOM: AURA, BY CARLOS FUENTES
}

\section{María Dolores Albaladejo García}

\section{Instituto Cervantes}

RESUMEN: El presente artículo ofrece una propuesta para la explotación de textos literarios extensos, originales y completos en el aula de español como lengua extranjera (ELE), a través de una serie de actividades de carácter comunicativo, participativo y lúdico, basadas en la novela breve del escritor mexicano Carlos Fuentes titulada Aura. En él se muestra cómo puede hacerse la explotación y seguimiento de dicho texto cómodamente, mediante la combinación del trabajo en el aula y en casa, así como la adecuada elección y explotación didáctica de los puntos cruciales del texto. El objetivo final del ensayo es ofrecer al docente las herramientas necesarias para llevar a cabo la lectura de un texto literario completo en la clase de ELE, tarea harto difícil tanto para el profesor como para el alumnado, y que dicha experiencia resulte satisfactoria y enriquecedora para el estudiante de español, de forma que le anime a seguir leyendo en la lengua meta.

Palabras clave: explotación, obras, literarias, completas, ELE.

ABSTRACT: The present article offers a proposal for the exploitation of extensive, original and complete literary texts in the Spanish as a Foreign Language classroom, through a series of activities of communicative, participative and playful character, based on the brief novel Aura, by the Mexican writer Carlos Fuentes. The essay shows how the exploitation and follow-up of the mentioned text can be done comfortably, by combining in the classroom and in house work, as well as the suitable choice and didactic exploitation of the crucial points of the text. The final aim of the study is to offer the teacher the necessary tools to carry out the reading of a complete literary text in the Spanish class, a difficult task indeed both for the teacher and for the students, and that the above mentioned experience turns out to be satisfactory and wealth-producing for the student of Spanish, so that it encourages him to continue reading in the target language

Key words: exploitation, complete, literary, works, Spanish.

Albaladejo García, M. D. (2015). La lectura de obras completas en el aula de Español como Lengua Extranjera: Aura, de Carlos Fuentes. Espiral. Cuadernos del Profesorado, 8(16), 19-40. Disponible en: http://www.cepcuevasolula.es/espiral.

Fecha de recepción: 14/11/2014

Fecha de aceptación: 12/02/2015
Enviar correspondencia a:

lolalbaladejo@hotmail.com

\section{1.- INTRODUCCIÓN}

Creo no equivocarme al afirmar que todos nosotros, como profesores de Español como Lengua Extranjera (ELE), alguna vez hemos experimentado una situación similar a la que describo: nos encontramos a mitad de curso, vamos retrasados con la programación fijada o al menos algo justos 
de tiempo, llegamos al final de una unidad didáctica que incluye un texto literario — un poema, un fragmento de novela o relato-, y concluimos que el tiempo en este momento es demasiado valioso para desaprovecharlo leyendo un texto que muy probablemente los estudiantes no van a entender, y que habría que invertir mucho tiempo y esfuerzo para que llegaran a hacerlo. Pensamos que de todas formas el texto está totalmente desvinculado de la unidad, que las tareas que propone el manual son irrelevantes dentro del programa previsto a nivel gramatical, y llegamos a la conclusión de que si no llevamos a cabo esta tarea de lectura no perjudicamos ni interferimos en el proceso de aprendizaje de los alumnos. Así pues, en un proceso mental que dura tan sólo unos segundos, pasamos la página y comenzamos una nueva unidad didáctica. Pero, ¿y si alguien propusiera además la descabellada idea de incluir una novela completa en el programa de curso?

Basándonos en la novela breve de Carlos Fuentes, Aura, con el presente artículo pretendemos transmitir la idea de que una obra literaria no es un texto inabarcable en la clase de ELE, ni un material que no facilite el aprendizaje de un idioma extranjero, ni pueda generar actividades comunicativas o tareas que desarrollen e integren las actividades de recepción, producción, interacción y mediación, y mucho menos un material aburrido y falto de interés para el alumnado.

Muy por el contrario, el texto literario como recurso didáctico se presta a múltiples manipulaciones o usos, al igual que cualquier otro instrumento con el que normalmente trabajemos en nuestras aulas, generador de infinitas posibilidades de enseñar a través de sus líneas, y muy motivador por tratarse de un texto auténtico al que nuestros alumnos se tendrán que enfrentar en un futuro si continúan con el proceso de aprendizaje de español. La motivación, factor clave del aprendizaje como todos sabemos, no sólo vendrá dada en este caso por la autenticidad de los materiales, sino por el adecuado diseño de las tareas que se desprendan de él, que deben ser de carácter comunicativo y participativo, añadiendo siempre un matiz lúdico que mantenga vivo el interés por interactuar, y sobre todo continuar con la lectura del texto. Con referencia al tiempo, gran obstáculo para la mayoría de los docentes al llevar a clase la lectura de obras literarias, y como esperamos también mostrar a lo largo de este análisis, es un elemento con el que podemos jugar, adaptándolo a nuestras necesidades y limitaciones.

Desde la experiencia en el aula de ELE, queremos demostrar que con una buena elección del texto, que tenga en cuenta factores tan importantes como la edad e intereses particulares de los alumnos, la dificultad y extensión del texto, el tiempo, el espacio y los medios materiales a nuestro alcance, junto con un cuidadoso y variado diseño de actividades, y haciendo uso de estrategias y recursos como los que presentaremos en este ensayo, obtendremos un resultado más que satisfactorio, tanto para el profesorado como para los educandos, logrando llevar a cabo la doble tarea de lograr el aprendizaje de español a través de los textos literarios y acercar a nuestros alumnos a la literatura en lengua española.

\section{2.- EXPLOTACIÓN DIDÁCTICA}

Como ya hemos anunciado, la obra seleccionada para llevar a cabo este estudio es Aura ${ }^{1}$, novela corta del escritor mexicano Carlos Fuentes. Con cincuenta páginas, consideramos que consta de una extensión apropiada para incluirla en un curso de español de unos tres meses de duración aproximada, o sesenta horas lectivas ${ }^{2}$, pues puede hacerse su explotación y seguimiento cómodamente durante el mismo realizando parte del trabajo en el aula y el resto en casa.

En cuanto a la dificultad del texto, un análisis del mismo nos revela que la novela se encuentra íntegramente escrita en los tiempos de Presente y Futuro simple, incluyendo algunas formas del Condicional y Subjuntivo, que predominan visiblemente los períodos oracionales de escasa longitud, y las intervenciones de los personajes en los diálogos son igualmente muy breves. Asimismo, es significativo el gran número de oraciones yuxtapuestas y coordinadas copulativas que encontramos, así como de subordinadas adjetivas, todas ellas sin ninguna dificultad sintáctica aparente o cambios de orden que dificulten su lectura e interpretación. Valorados todos estos rasgos gramaticales en su conjunto, por tanto, consideramos que la dificultad de la obra reside mayormente en el vocabulario y expresiones utilizadas, así como en la interpretación de los acontecimientos del relato, y es por ello 
que en el proceso de diseño de las actividades se le ha dado mayor énfasis a la explotación del léxico e interpretación de los sucesos que tienen lugar en la novela.

Aunque, como hemos apuntado, a nivel gramatical el texto no reviste mayor dificultad a simple vista, creemos que la complejidad interpretativa y del lenguaje lo hacen indicado para estudiantes de español en un nivel Superior C1, de una misma o de diferente procedencia, aunque el profesor podría juzgarlo apropiado en determinados casos para un nivel Avanzado B2. El carácter del texto, por sus imágenes, ritos y referencias a aspectos del mundo de la brujería, del sueño y lo desconocido, así como escenas de cierto contenido sexual, lo podrían hacer complejo para alumnos todavía en la adolescencia, por lo que sería más adecuado llevar a la práctica su explotación con adultos.

Para llevar a cabo la explotación didáctica del texto, presentamos diversas actividades de creación propia diseñadas a partir de las características particulares de la novela, y el resto son adaptaciones al texto y/o variaciones de las propuestas por Collie y Slater (2002), las técnicas creativas de Gianni Rodari (1973), y el estudio de la consigna en los talleres latinoamericanos de Delmiro Coto (2002). Dichas actividades se plantean sin predominio particular de una destreza determinada, puesto que a través de ellas se pretende lograr la práctica global de las actividades comunicativas de la lengua de forma integradora. Depende de los objetivos perseguidos por el profesor la elección de las actividades, y por tanto la preeminencia de una destreza sobre las demás. Las dinámicas que se trabajan con el uso de las actividades presentadas son básicamente todas las posibles dentro de un aula de enseñanza de lengua, es decir, individual, en parejas, grupal y plenaria.

Con referencia al tiempo necesario para llevar a cabo las tareas que se presentan, éste dependerá del número y características de las actividades que elija el profesor para su clase, ya que no es necesario poner en práctica todas ellas, sino aquellas que se adecúen mejor a los rasgos particulares del grupo: el número de alumnos, su edad e intereses personales, el tiempo del que se disponga, las destrezas que se pretendan desarrollar, e incluso el espacio y recursos materiales disponibles.

Finalmente, solo queda añadir que la propuesta diseñada queda dividida en tres partes que denominaremos de la siguiente forma: Actividades de pre-lectura, Actividades de explotación de puntos cruciales o seguimiento y Actividades finales o de cierre.

\section{3.- SECUENCIA DIDÁCTICA}

\section{A. Actividades de pre-lectura}

En esta primera sección el objetivo principal es múltiple. Por una parte, pretendemos preenseñar el nuevo vocabulario que aparece en la obra, con el fin de hacerlo familiar y que el comienzo de la lectura sea una experiencia fácil y gratificante para el alumno. Por otra parte, tratamos de explorar los temas principales que sustentan la novela, para extraer los pensamientos y sentimientos de los estudiantes acerca de los mismos. Finalmente, procuramos despertar el interés y la curiosidad del alumno por leer el libro.

Para ello, presentamos una selección de cuatro actividades en las que se trabaja fundamentalmente con la portada, el título, el autor del libro y el primer fragmento de Aura. Queda a discreción del docente el uso de una o varias de las actividades propuestas, atendiendo a las características específicas de su grupo. Las actividades planteadas y los pasos de las mismas son los siguientes:

\section{Montaje biográfico y El aura y sus colores}

a. Un día o dos antes de llevar a cabo la presentación del texto en clase, el profesor explica a los estudiantes que van a leer una novela corta de Carlos Fuentes. No les da más información y divide a los alumnos en dos grandes equipos. El primer equipo se encargará de buscar información de todo tipo (vida, fotos, obras, período y escritores coetáneos, país, fechas, nombres de lugares, etc.) relacionada con el autor de la obra que van a leer. El segundo equipo buscará información sobre el aura y el significado de sus colores. 
b. El día previsto para traer toda la información recogida a clase y hacer una puesta en común de la misma, cada equipo expondrá ante el resto de los compañeros sus hallazgos, explicando los datos, las fotos que hayan encontrado, las noticias, los vídeos, etc. sobre los dos temas propuestos.

c. Una vez expuesto todo el material, el profesor puede realizar las actividades de seguimiento que se detallan a continuación:

1.- Sobre Carlos Fuentes: el profesor trae cartulina a la clase y los alumnos crean un poster o collage sobre la vida y obra del autor con las fotos que hayan encontrado (también pueden hacer 22 dibujos, escribir fragmentos de un texto suyo o incluir objetos relacionados con el autor, su país, sus costumbres, etc.), a las que tendrán que escribir un subtítulo o texto corto debajo para crear una biografia ilustrada del mismo. Pueden hacerse varios subgrupos y crear varios montajes para después votar el más original, divertido, loco, colorido, etc. Finalmente se exponen las producciones en un muro en el aula.

2.- Sobre el aura y sus colores: los alumnos deberían haber explicado en la puesta en común anterior en qué consiste el aura de una persona y el significado de cada uno de sus colores. Si los estudiantes no lo han hecho, el profesor puede poner en clase el vídeo titulado "El aura humana" (4:14 minutos) que encontrará en Youtube, en el que se explica brevemente qué es el aura y sus colores. Después puede hacer una lluvia de ideas sobre las auras más "famosas" o conocidas por todos (la representación de Dios, Jesucristo, la virgen María, los santos, Buda, etc.) y abrir un pequeño debate o discusión sobre el tema: ¿creen que existe realmente el aura de una persona? ¿Alguien en la clase lo ha visto alguna vez o conoce a alguien que puede verlo? ¿Por qué el aura de Jesucristo, la virgen, etc. se representa de color azul y la de Dios de blanco? ¿Por qué el aura de Buda es de color dorado siempre?

Para terminar, cada alumno debe decir de qué color cree que es el aura de su compañero/a (de acuerdo a lo expuesto por ellos mismos y en el vídeo) y explicar por qué. La persona aludida expresará su acuerdo o desacuerdo con su compañero/a. Después, en grupos pequeños o parejas, los alumnos deben decidir de qué color creen que es el aura del profesor y razonar su decisión ante la clase.

\section{Predicciones}

El profesor muestra una transparencia de la portada del libro (Anexo I) en el retroproyector cubriendo el título y pide a la clase que describa lo que ve, haciendo preguntas como: ¿alguien tiene o ha tenido un gato negro en casa? ¿Qué significado tiene un gato negro en vuestra cultura? ¿Con qué se relaciona normalmente?, y tomando nota de las sugerencias en la pizarra. Después muestra el título y pide que lo relacionen con el dibujo de la portada y con el posible desarrollo de la historia que van a leer. Finalmente, el profesor, o un alumno designado para tal fin, conserva un registro de las especulaciones para comparar posteriormente.

\section{La cápsula del tiempo}

Se enseña a los estudiantes el primer fragmento de la obra como transparencia en el retroproyector (Anexo II). Se les pide que lo lean de forma individual y se les da una tarjeta o trozo de papel en blanco, donde cada alumno tiene que escribir su predicción acerca de cómo se va a desarrollar la historia hasta el final, sin sobrepasar la extensión de la tarjeta o papel que se les ha entregado. El profesor recogerá las predicciones y las meterá en un sobre donde previamente ha escrito "Cápsula del tiempo" en la parte exterior, y que se cerrará hasta el final de la lectura del texto. Para activar su imaginación pueden hacerse preguntas tipo: ¿Qué creéis que hará el protagonista con el anuncio? ¿Se presentará o no? Parece que la suma ofrecida por el trabajo es muy elevada, ¿de qué creéis que se tratará realmente el trabajo? ¿Qué pensáis que va a pasar?, etc.

\section{Anuncio personalizado}

Los alumnos deben redactar un anuncio dirigido a un compañero de la clase siguiendo el modelo del que acaban de leer y con la información que disponen de dicha persona. Para ello, el profesor pide que escriban su nombre en un papelito, lo cierran y cada estudiante coge uno al azar. Cada alumno redacta su anuncio, dejando en blanco la parte donde dice el nombre de la persona a la que va dirigido. Finalmente, el profesor recoge todos los anuncios y los redistribuye en la clase. Cada 
uno lee el anuncio que le ha caído en suerte y el resto debe adivinar a quién va destinada la oferta de trabajo.

Por supuesto, se debe animar a los alumnos a que se empleen a fondo en cuanto a corrección, léxico y estilo, además de usar todas sus dotes de imaginación para crear un anuncio que después pueda sonar lo más profesional posible, con una buena dosis de humor si así lo prefieren.

El profesor ha de entregar a los alumnos una fotocopia con el primer fragmento que ya han leído si decide que deben hacer la redacción del anuncio en casa, o simplemente se continúa con el texto expuesto en el retroproyector si la llevan a cabo en clase.

\section{B. Actividades de explotación de puntos cruciales y de seguimiento}

En esta segunda sección, y al combinar la lectura en casa con el trabajo en clase de forma que en el aula se trabajen los fragmentos más significativos del texto, dejando el resto para una lectura complementaria individual, pretendemos alcanzar numerosos objetivos: por una parte, tratamos de mantener vivo el interés de los estudiantes por la lectura y la sensación de conjunto en clase, al mantener una visión global de la obra en todo momento. Consideramos que la idea de continuidad es clave para lograr la implicación de los alumnos, de forma que éstos se sientan vinculados a un proyecto común en el aula. Por otra parte, procuramos explotar didácticamente los momentos culminantes de la historia, ayudando al mismo tiempo al alumno a comprender el texto a nivel de lenguaje, ideas y caracterización mediante actividades que fomentan el desarrollo e integración de las competencias comunicativas de la lengua. Finalmente, pretendemos estimular la reacción personal del alumno ante el texto, proporcionando a éste la satisfacción de haber leído una obra completa en español.

Con este fin, aportamos una amplia variedad de actividades, en total nueve, que giran en torno a los momentos cruciales de la obra, la comprensión global del texto, las dificultades de lengua y el propósito último de mantener despierto el interés del alumno por la lectura de la novela, de entre las cuales el docente podrá seleccionar las que considere más apropiadas. No se trata de apabullar al alumnado con una multitud indiscriminada de tareas, sino de elegir aquellas que mejor se adecuen a nuestra clase. Para ello, como ya apuntamos anteriormente, hemos de sopesar factores como la edad de los alumnos, el interés particular de éstos hacia la lectura, sus preferencias de aprendizaje, y por tanto su disposición a llevar a cabo cierto tipo de actividades en detrimento de otras, el tiempo y el espacio físico del que disponemos o los medios materiales a nuestro alcance para su realización. La secuencia de actividades presentadas queda como sigue:

\section{Actividades para trabajar el lenguaje del texto: emparejar, definir y completar expre- siones}

Los estudiantes llevan a cabo diversas actividades para trabajar el léxico complejo y las expresiones novedosas del texto. Se dan sinónimos, definiciones de palabras o expresiones parafraseadas para emparejar con la palabra o expresión que corresponda. Después, deben utilizar este mismo vocabulario en una tarea de seguimiento en la que han de completar oraciones, con el fin de asegurarnos de la completa comprensión del léxico al tener que usarlo en un contexto significativo diferente (Anexo III).

\section{Actividades de comprensión e interpretación de la lectura: cuestionario con seguimiento}

Se trata de un cuestionario de diez preguntas basadas en el texto que han leído. La tarea puede realizarse en clase o en casa, aunque por cuestión de tiempo sería mejor en casa. Posteriormente en clase se llevan a cabo las actividades de comprensión e interpretación de la lectura que se acompañan en el Anexo IV en grupos pequeños y en gran grupo.

\section{Resumir el resumen}

Se divide la clase en tres grupos o más, dependiendo del número de alumnos. Cada grupo hace un resumen del texto leído de un número determinado de palabras, por ejemplo 100. Se pasan los resúmenes creados al siguiente grupo y tienen que reducirlo a la mitad, 50 palabras. Se pasan de nuevo y se reducen a 25 palabras. Por último, se leen y comparan las versiones finales. Al tener que sintetizar 
los acontecimientos clave de la obra, con esta actividad lograremos saber si los alumnos han captado y asimilado la esencia de la novela en su totalidad.

\section{Epitafio}

Los estudiantes, basándose en el carácter del general Llorente por los datos obtenidos a través de la lectura de sus memorias, escriben un epitafio para su tumba (Anexo V). Esta actividad puede llevarse a cabo de forma individual, en parejas o en pequeños grupos. Más tarde, se hace una puesta en común y se puede hacer una votación sobre el más original, apropiado, poético, irónico, etc. y opcionalmente exponerlos en un muro en el aula.

\section{Retratos dictados}

En esta obra encontramos la descripción física detallada de dos de sus protagonistas: Felipe (Pág. 141) y la Señora Consuelo (Págs. 136 y 180). En parejas, un alumno lee en voz alta a su compañero la descripción de uno de los personajes y éste lo dibuja conforme va escuchando. Después invierten los papeles. En cuanto al personaje de Aura, hay una descripción exhaustiva de sus ojos (la única parte de su cuerpo que aparece descrita en el texto, aunque también sabemos que tiene el pelo negro y siempre va vestida de verde) en las páginas 139-40. En las mismas parejas y conjuntamente, hacen un bosquejo de Aura teniendo en cuenta la descripción de sus ojos y su propia imaginación del resto. La cuestión a plantear a los alumnos es: ¿Cómo imagináis a Aura? Los estudiantes deben exponerlo a la clase y explicar por qué se la imaginan de esa forma. De nuevo, puede realizarse una votación y/o exposición en clase de los dibujos.

\section{Lecturas paralelas: animales novelescos}

El profesor divide la clase en cuatro grupos, que corresponderán a cada uno de los animales que aparecen en el texto de forma reiterada: el perro, el gato, el conejo y el macho cabrío ${ }^{3}$. Les pregunta al conjunto de los alumnos: ¿Qué características se les atribuye a estos animales en vuestra cultura? ¿Con qué se les relaciona? Cada equipo busca el significado simbólico del animal que le corresponde en internet si se tiene acceso a éste en el aula, o simplemente discuten entre ellos la información que ya posean, y deben encontrar relaciones con los personajes, objetos que aparecen en la historia o con el desarrollo de la misma.

Cuando se haya acabado la discusión en grupo y alcanzado un acuerdo, un alumno de cada equipo se sentará con otro equipo, de forma que en cada grupo haya un representante de cada animal, y expondrá las conclusiones a las que ha llegado con sus compañeros.

Finalmente, el profesor entrega a cada grupo un pequeño texto en el que se habla del significado simbólico de estos animales ${ }^{4}$ (Anexo VI). Lo leen entre todos dentro de su propio equipo, y de nuevo un alumno de cada grupo se sitúa con los miembros de otro para contarles (esta vez sin el texto que ha entregado el profesor) con sus propias palabras la información que han recibido. Tras esto, cada equipo hará una exposición en clase sobre lo discutido y se hace una puesta en común entre todos.

\section{Adaptaciones teatrales}

Se divide la clase en varios grupos y se les pide a los alumnos que elijan una escena que consideren crucial para la historia. Una vez hecho esto, se les explica que deben elaborar una representación para el teatro o la televisión e interpretarla en clase. Si hay tiempo pueden hacerlo con ropa adecuada, escenario, música o los objetos que crean necesarios. Una buena elección en caso de que pidan consejo al profesor sería la escena inicial del encuentro de Felipe con la Señora Consuelo y Aura (Págs.135-40), o en la que Felipe dialoga con Aura sobre una posible huida juntos (Págs. 17172). Si el profesor así lo desea, puede hacer que los estudiantes reescriban el diálogo de la escena que van a representar con sus propias palabras e incluso ofrecer la posibilidad de cambiar la línea del discurso.

\section{Trivial de novela}

Se trata de un juego basado en la novela que acaban de leer en el que los estudiantes tienen que agudizar y combinar su capacidad de comprensión de la lectura con la memoria de lo leído y su rapidez de respuesta. 
El juego consiste en responder a las preguntas que aparecen en las fichas (Anexo VII) de la forma más precisa y rápida posible. Para ello, una vez dividida la clase en dos equipos, tienen que levantar una tarjeta por turnos, fijándose un sistema de puntos y penalizaciones en caso de acierto o error en la respuesta (Anexo VIII).

Finalmente, el profesor, que habrá hecho de moderador del juego y dará las respuestas por correctas o incorrectas, sumará los puntos obtenidos, que habrá anotado en la pizarra, y se sabrá quién es el equipo ganador del Trivial de novela.

En cuanto a las respuestas correctas, el profesor decidirá si dar la respuesta de forma inmediata tras haber agotado los dos equipos todos los pasos, o indicarles a los alumnos en qué página se encuentra la respuesta para que la busquen al final del juego. Si se realiza de esta forma, se llevará a cabo una puesta en común de las respuestas encontradas.

\section{Tráiler}

En grupos, los alumnos tienen que diseñar un tráiler de dos minutos para promocionar la película sobre la obra que están leyendo. Un alumno lee en voz en off la presentación de la película y el resto escenifica o adopta posiciones congeladas sobre las escenas más dramáticas de lo que va diciendo la voz en off. Antes, los estudiantes han tenido que decidir en equipos cuales son los puntos culminantes de la misma para representarla.

Se nombra un comité cinematográfico que irá puntuando las actuaciones y resultado final del tráiler (por ejemplo de 1 a 5 puntos) y, tras cada representación, cada miembro del jurado muestra su puntuación razonándola. El profesor irá sumando los puntos de cada miembro y anotando en la pizarra la puntuación obtenida por cada equipo. Ganará el equipo que más puntos obtenga al final.

\section{C. $\quad$ Actividades finales o de cierre}

El propósito de la última fase de la presente explotación didáctica de Aura consiste en conservar el sentido global de la obra literaria, a la vez que involucramos activamente a los alumnos en la puesta en común de opiniones.

De nuevo, el abanico de actividades diseñadas con este fin es amplio, ocho en este caso, que tratan de dar un sentido de conjunto y conclusión al proceso de lectura, manipulación del texto y comprensión del mismo. A continuación describimos dichas tareas:

\section{Diseños de cubierta}

En parejas, individualmente o en grupos pequeños, los alumnos imaginan que trabajan para el departamento gráfico de una editorial y que van a publicar la obra que han leído. Tienen que diseñar la cubierta para su publicación, teniendo en cuenta que el diseño tiene que representar la esencia del libro y atraer a lectores potenciales. Para ello pueden dibujar, usar fotos de revistas, un programa de ordenador o se les puede dar un juego de tarjetas con figuras geométricas de diferentes formas y colores para que las combinen para formar figuras abstractas o simbólicas. Se hace una exposición y tienen que explicar el sentido del diseño y el efecto que quieren comunicar.

\section{Esculpir}

Se escriben los nombres de los personajes de la historia en trozos de papel y se echan a una bolsa. Se elige un escultor y el resto coge un papel cada uno. El escultor nombra a un personaje y le da instrucciones de cómo se debe colocar en el "área de escultura". Nombra a otro personaje y lo sitúa en relación al anterior dependiendo de su relación en la historia. Cuando la escultura está completa el escultor tiene que explicar por qué los ha situado asi ${ }^{5}$ (Anexo IX).

\section{Abrir la cápsula del tiempo}

Si se hizo la actividad "sellar la cápsula del tiempo" al principio, ahora se abre y cada alumno tiene que explicar por qué hizo las predicciones y qué pasó en realidad para que se cumplieran o no. Seguidamente, se hace una puesta en común y/o votación sobre las hipótesis que más se han acercado al desarrollo real de la historia.

\section{Discurso apócrifo: memorias inconclusas}


Se divide la clase en grupos de tres como máximo. Los alumnos deben releer la última parte de las memorias del General Llorente (Págs. 175-76) e inventar un final, respetando el estilo utilizado por el general. Se hace una puesta en común con toda la clase y se puede votar el más original, creíble, disparatado o imaginativo.

\section{Adaptación para otra audiencia}

Los estudiantes deben reescribir el texto para dirigirse a otro tipo de audiencia, por ejemplo un niño, un director de películas de terror, un cómic o contar la historia como si fuera un cuento de hadas, para lo cual se les da el comienzo de la historia en el tono y estilo del género elegido. Por ejemplo, si decidimos que sea un cuento de hadas podría empezar como: "Érase que se era un príncipe joven y guapo llamado Felipe. Se encontraba en su palacio, cuando un día llegó un mensajero...". El profesor puede establecer un máximo de palabras o dejarlo a voluntad de los alumnos.

\section{Inventar un final}

Los estudiantes, en parejas o pequeños grupos, escriben un final para la historia. En caso de optar por esta actividad, el profesor deberá haber eliminado la última parte de la misma desde el principio, es decir, desde la página 178, donde dice: "Repetirás: -Aura...", y no haber llevado a cabo actividades como la "Cápsula del tiempo" para que sea efectiva. Una vez más, se hace una puesta en común en la que cada pareja o grupo razona su propuesta y por último se les entrega o visualiza en retroproyector el final para que comparen y comenten las diferencias.

Una variación posible sería que cada miembro del equipo, situado en círculo, escriba una frase y lo pase a su compañero/a de la derecha, obteniendo así varios finales elaborados colectivamente en cada grupo.

\section{Escuchar la canción}

Hay un bolero muy popular titulado "Aquellos ojos verdes". Resultaría una buena opción escucharlo a modo de colofón de la lectura, por su relación con la protagonista de la historia, cuyos ojos verdes son lo más significativo de su persona a lo largo de todo el relato. Existen tres versiones disponibles en youtube: de Nat King Cole, Los Panchos y de Plácido Domingo. Aunque la versión original pertenece a Los Panchos, por motivos de calidad en el sonido, trabajaremos sobre la letra perteneciente a Plácido Domingo (Anexo X).

\section{Adaptaciones al cine}

Existen dos cortometrajes ${ }^{6}$ basados en la novela corta de Fuentes, uno dirigido por José Luís Alanís y producido por Perro Noble de 29:57' de duración, y el segundo dirigido por Ana Cárdenas y producido por IF de 14:59'. Ambos pueden visionarse en Youtube. Por su extensión, cualquiera de los dos puede verse en clase, e incluso los dos si se desea ${ }^{7}$.

La primera propuesta de explotación está basada en el cortometraje de Perro Noble. Los alumnos pueden verlo e ir anotando las diferencias que encuentren con la obra, tras lo cual se haría una puesta en común con toda la clase sobre dichas diferencias (Anexo XI) y se abriría un pequeño debate basado en cuestiones como: ¿imaginabais así a los personajes? ¿Y la casa? ¿Qué cosas os han sorprendido (por ejemplo: el ordenador o los espaguetis)? ¿Creéis que se ha conservado la esencia de la novela o se han perdido matices importantes? ¿Cuáles?, etc. Una variante a esta actividad sería dividir la clase en dos equipos, y que durante el visionado cada equipo anotara las diferencias el primero y las semejanzas el segundo. El resto se desarrollaría de la misma forma.

Finalmente, una segunda propuesta consiste en visionar los dos cortometrajes y que los alumnos descubran las diferencias entre los dos, y entre estos y la versión escrita. En este caso, durante la puesta en común, el debate giraría en torno a preguntas como: ¿Cuál os ha gustado más y por qué? ¿Cuál creéis que es más fiel al original? ¿En qué aspectos? Al ampliarse la tarea a dos visionados, sería conveniente hacer equipos de trabajo para que ésta no resulte demasiado extensa y laboriosa.

\section{3.- CONCLUSIONES}


A lo largo de este trabajo esperamos haber logrado mostrar cómo el hecho de llevar una obra literaria completa a nuestra clase de ELE no es una idea descabellada ni una tarea inabarcable, y además constituye una excelente vía de promover el aprendizaje del español en nuestros educandos.

Como también deseamos haber demostrado, el número y variedad de actividades que se pueden crear alrededor de un texto literario es prácticamente ilimitado, aquí solamente hemos mostrado un buen elenco de ellas, pero no son las únicas que podrían diseñarse. Al elaborar y hacer uso en nuestras aulas de una rica y variada batería de actividades apropiadas al alumnado y al texto seleccionado, nos alejamos del modo tradicional de trabajar un texto, en el que tras la lectura se responde a preguntas sobre el mismo que casi se dan por contestadas en sus líneas o a cuestiones que nada tienen que ver con dicho texto, pues este sólo sirve de pretexto para tratar de otro tema, y optamos por explotar didácticamente el material literario de una forma interactiva, divertida y creativa tanto en casa como en el aula, alternando y simultaneando los dos modelos de trabajo para que la lectura de la obra elegida se convierta en un proyecto integrado en el aula, vinculante y de continuidad, del que los alumnos se sientan parte activa.

De esta manera, también, nuestros alumnos no solo encontrarán múltiples y variadas formas de encuentro y aprendizaje de la lengua meta, sino que la lectura se convertirá en una experiencia amena y satisfactoria, alejada de la frustración que muchas veces conlleva el intento de abordar un texto en lengua extranjera, revirtiendo finalmente en la satisfacción personal de haber leído una obra íntegra en español, con lo que con gran seguridad habremos contribuido a fomentar su deseo de continuar leyendo otros textos literarios en lengua española.

Con nuestra aportación confiamos además haber contribuido a romper con el estigma que pesa sobre la literatura desde hace tantos años, y que la señala como una forma estética y elevada del lenguaje a la que los estudiantes de español como lengua extranjera no pueden llegar, o al menos hasta que no alcancen un nivel muy avanzado de la lengua meta. Los alumnos, al igual que los profesores de ELE, deben perder el miedo a enfrentarse a un texto literario y aprender a manejarlo, moldearlo, jugar con él como algo vivo, haciéndolo real y cercano a ellos mismos. Así debemos entenderlo nosotros como docentes, y transmitirlo a ellos, nuestros aprendices, para que el proceso de enseñanzaaprendizaje sea efectivo.

\section{4.- REFERENCIAS}

Collie, J. y Slater, s. (2002). Literature in the Language Classroom: A Resource Book of Ideas and Activities. Cambridge: Cambridge University Press.

Delmiro Coto, B. (2002): La escritura creativa en las aulas. En torno a los talleres literarios. Barcelona: Graó.

Eudave, C. (2001): Simbolismo y ritualidad en la novela Aura de Carlos Fuentes. En: www.literaturas.com/auracarlosfuentesceudave.htm

Fuentes, C. (1962). Aura. En: Cuentos sobrenaturales. Madrid: Alfaguara, 2007.

Rodari, G. (1973): Gramática de la fantasía: Introducción al arte de contar historias. Barcelona: Ediciones del Bronce, 2002.

Salazar García, V. (2012). A propósito de las actividades para la enseñanza de los adjetivos en el aula de ELE. En. E. T. Montoro de Arco (ed.), Neología y creatividad lingüística. Anejo de la Revista Quaderns de Filologia, 77, 169-182. Valencia: Universidad de Valencia.

\section{PUBLICACIONES RELACIONADAS CON EL TEMA}

Albaladejo García, M. D. (2005). Actividades comunicativas para la enseñanza de ELE a través de la literatura. En Actas del Congreso Internacional "Retos del hispanismo en la Europa Central y del Este". Cracovia.

Albaladejo García, M. D. (2004). Marco teórico para el uso de la literatura como instrumento didáctico en la clase de E/LE (I). En Revista del Instituto Cervantes de Estambul, 7.

Albaladejo García, M. D. (VI/2006). "Aplicación práctica de los principios teóricos para una enseñanza comunicativa de E/LE a través de la literatura" (II). En Revista universitaria Románica Cracoviensia. Universidad Jaquelónica, Cracovia. 
Albaladejo García, M. D. (2006). Enfoques y criterios de selección de textos literarios para la clase de E/LE. En Actas del XVII Congreso Internacional de A.S.E.L.E. Logroño.

Albaladejo García, M. D. (2007). Cómo llevar la literatura al aula de ELE: de la teoría a la práctica. En Revista MarcoELE, 5. Documento disponible en: http://marcoele.com/numeros/numero-5/

Albaladejo García, M. D. (2012). Interculturalidad y lengua en la clase de español: La discusión por señas". En Actas de las IV Jornadas de Formación para Profesores de Español. Chipre. Documento disponible en: http://www.ucy.ac.cy/langce/documents/Projects/ACTAS JORNADAS_ELE_CHIPRE_2012.pdf

\section{EXPLOTACIÓN DIDÁCTICA DE RELATOS Y POEMAS}

Albaladejo García, M. D. (2005-2014). Documentos disponibles en Revista MarcoELE: www.marcoele.com

- "Jacinto", de Mario Benedetti

- “Cuando la mujer abre la puerta”, de Quim Monzó

- "Espantos de agosto", de Gabriel García Márquez

- "A un hombre de gran nariz", de Francisco de Quevedo

- "Griselda", de Amparo Dávila

- "Dos palabras", de Isabel Allende

- “El puercoespín mimoso", de Mario Benedetti

- "Un día de estos", de Gabriel García Márquez

- "El rastro de tu sangre en la nieve”, de Gabriel García Márquez 


\section{ANEXOS}

\section{ANEXO I:}

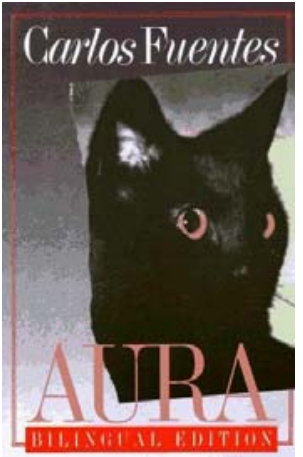

\section{ANEXO II:}

LEES ESE ANUNCIO: UNA OFERTA DE ESA NATURALEZA no se hace todos los días. Lees y relees el aviso. Parece dirigido a ti, a nadie más. Distraído, dejas que la ceniza del cigarro caiga dentro de la taza de té que has estado bebiendo en este cafetín sucio y barato. Tú releerás. Se solicita historiador joven. Ordenado. Escrupuloso. Conocedor de la lengua francesa. Conocimiento perfecto, coloquial. Capaz de desempeñar labores de secretario. Juventud, conocimiento del francés, preferible si ha vivido en Francia algún tiempo. Tres mil pesos mensuales, comida y recámara cómoda, asoleada, apropiada estudio. Solo falta tu nombre. Solo falta que las letras más negras y llamativas del aviso informen: Felipe Montero. Se solicita Felipe Montero, antiguo becario en la Sorbona, historiador cargado de datos inútiles, acostumbrado a exhumar papeles amarillentos, profesor auxiliar en escuelas particulares, novecientos pesos mensuales. Pero si leyeras eso, sospecharías, lo tomarías a broma. Donceles 815 . Acuda en persona. No hay teléfono.

\section{ANEXO III:}

\section{ACTIVIDADES PARA TRABAJAR EL LENGUAJE DEL TEXTO}

1. AMERICANISMOS. En Aura aparecen abundantes americanismos. Busca cada palabra de las que te presentamos a continuación en el texto y relaciónala con su sinónimo o definición en español peninsular:
a. Camión (pág. 132)
b. Bolsa (pág. 132)
c. Expendio (pág. 133)
d. Sinfonola (pág. 133)
e. Manija (pág. 133)
f. Tapete (pág. 134)
g. Veladora (pág. 135)
h. Recámara (pág. 139)
i. Tina (pág .141)
j. Saco (pág. 142)
k. Platón (pág. 144)

1. Escarapelado (pág. 158)
1. Asa, parte por la que se agarra un objeto.

2. Habitación, alcoba o aposento.

3. Alfombra pequeña.

4. Chaqueta, americana.

5. Desconchado. Pared que ha perdido su enlucido.

6. Bolsillo de las prendas de vestir.

7. Autobús.

8. Recipiente de gran tamaño, fuente.

9. Bañera.

10. Máquina tocadiscos que funciona con monedas.

11. Lamparilla que consta de una vasija de aceite o parafina y una mecha.

12. Tienda pequeña donde se vende al por menor.

2. EXPRESIONES. Busca las siguientes expresiones en el texto y explica su sentido con una palabra, definición o expresión que signifique lo mismo:

a. Tomar la delantera (pág. 132)

b. Ir al grano (pág. 136) 
c. (A) ras de suelo (pág. 137)

d. Con cautela (pág. 142)

e. Caminar de puntas (pág. 155)

f. A gatas (pág. 162)

g. A tientas (pág. 164)

h. De cuclillas (pág. 167)

3. LÉXICO I. Relaciona cada palabra subrayada del texto con su sinónimo o definición (de la página 131 a la 154):

1. ...bajas la mirada al zaguán despintado y descubres 815 , antes 69 . (pág. 133)

2. ...sobre esa madera crujiente, fofa por la humedad y el encierro. (pág. 134)

3. ... esa cofia de seda que debe recoger un pelo muy blanco... (pág. 136)

4. ... esas migajas, esas costras de pan regadas sobre los edredones... (pág. 136)

5. Son sus memorias inconclusas. (pág. 137)

6. ...al mismo tiempo que ella, remedará el gesto. (pág.139)

7. ...sigues el susurro de la falda, el crujido de una tafeta. (pág. 140)

8. ...levantas los ojos hacia el tragaluz inmenso que hace las veces de techo. (pág. 141)

9. ...la lámpara antigua, de quinqué, luz opaca de tus noches de investigación. (pág. 141)

10. ...tina de cuatro patas, con florecillas pintadas sobre la porcelana, un aguamanil azul. (pág. 141)

11. ...y una botella vieja y brillante por el limo verdoso que la cubre. (pág. 143)

12. ...delgada como una escultura medieval, emaciada. (pág. 146)

13. ...las piernas se asoman como dos hebras debajo del camisón, flacas, cubiertas por una erisipela inflamada. (pág. 146)

14. ...Santa Lucía, el Arcángel Miguel, los demonios sonrientes, los únicos sonrientes en esta iconografía del dolor y la cólera. (pág. 146)

15. ...bajará la cabeza para quitarse ese listón morado. (pág. 148)

16. Camine y tropezará con el arcón... (pág. 148)

17. ...debes espaciar tu trabajo para que la canonjía se prolongue lo más posible. (pág. 152)

a. Lodo, cieno.

b. Infección cutánea caracterizada por una erupción rojiza y comúnmente acompañada de fiebre.

c. Tela delgada de seda muy tupida.

d. Demacrado, flaco.

e. Imitar una cosa.

f. Colección de imágenes o retratos de una época o un tema concretos.

g. Caja, arca grande, comúnmente de madera, sin forrar y con una tapa plana que va unida con bisagras por uno de sus lados y con candados o cerraduras por el opuesto.

h. Blando, de poca consistencia.

i. Especie de gorro femenino, que forma parte del uniforme propio de algunas profesiones.

j. $\quad$ Parte pequeña y menuda del pan, que suele saltar o desmenuzarse al partirlo.

k. Espacio cubierto, situado dentro de una casa e inmediato a la puerta de la calle.

1. Ventana abierta en un techo o en la parte superior de una pared.

m. Lámpara portátil de petróleo o aceite con un tubo de cristal para resguardar la llama.

n. Prebenda y dignidad del canónigo. Empleo de poco trabajo y bastante provecho.

o. Palangana o pila destinada para lavarse las manos.

p. No acabado.

q. Cinta de seda de menos de dos dedos de ancho. 
4. COMPLETAR ORACIONES: Completa las oraciones siguientes con la palabra apropiada del ejercicio anterior $^{8}$. Haz los cambios que creas necesarios:

a. Luis estuvo muy enfermo y ahora se ve extremadamente delgado y

b. La falda que me compré el otro día está hecha de azul.

c. Las enfermeras deberían llevar una

d. Al oír los ruidos, salió al pasillo con un por cuestión de higiene, como antiguamente.

e. El lavabo ha sustituido al para ver qué ocurría.

f. El párroco de la iglesia recibe un salario al mes por cuidar de la conservación del edificio. Esa le permite vivir con holgura, sin problemas económicos.

g. Cuando llego a casa, siempre dejo la bicicleta en el para que no me la roben.

h. Recoge las que estás dejando en el mantel después de comerte el bocadillo.

i. ¿Por qué no te recoges el pelo con un bonito?

j. Como hace tiempo que no hago deporte, siento que tengo los muslos

k. El hijo de Carmen tiene una enfermedad de la piel y sus brazos están cubiertos por una color rojo.

1. El escritor dejó una novela al morir. Su hijo, que también es escritor, dice que va a terminarla.

m. Mi abuela guarda en un de madera muy antiguo todos los recuerdos de familia.

n. La niña siempre intenta la forma de vestir de su madre.

o. La casa es tan oscura que han hecho un en el techo para que entre la claridad.

p. En el museo de la ciudad han abierto la exposición de medieval que esperábamos visitar.

q. Todas las botellas que tengo en la bodega están cubiertas de

5. LÉXICO II. Relaciona cada palabra subrayada del texto con su sinónimo o definición (de la página 155 a la 180):

A. Empujas la puerta y entras a esa recámara, también oscura, de paredes enjalbegadas... (pág. 155)

B. Un día la encontró, abierta de piernas, con la crinolina levantada por delante... (pág. 160)

C. ...en el momento en que degüella un macho cabrío. (pág. 161)

D. Corres a(1)... la cocina donde Aura despelleja al chivo lentamente. (pág. 161)

E. ...y te arrojas exhausto sobre ella, exhausto y abúlico. (pág. 162)

F. En silencio, moviendo su mano descarnada. (pág. 162)

G. ...y esa cabeza tonsurada, con los pliegues rotos de la falda entre las manos. (pág. 163)

H. ...la muchacha de ayer -cuando toques sus dedos, su talle. (pág. 166)

I. ...te ofrece la mitad de la oblea que tú tomas, llevas a la boca. (pág. 167)

J. ...en el recuerdo inasible de la premonición, que buscas tu otra mitad. (pág. 170)

K. ...en el recuerdo inasible de la premonición, que buscas tu otra mitad. (pág. 170)

L. ...apartas el candado, levantas la tapa y escuchas el ruido de los goznes enmohecidos. (pág. 174)

M. ....arenga a los hombres de honor contra el monstruo republicano. (pág. 175)

N. Le advertí a Consuelo que esos brebajes no sirven para nada. (pág. 175)

O. ...el traje abotonado hasta el cuello, el pañuelo en una mano, el polisón. (pág. 176)

P. ...sobre el cartón doblado del daguerrotipo, esa letra de araña. (pág. 176)

Q. ...la mujer que volverá a abrazarte cuando la luna pase, tea tapada por las nubes. (pág. 180)
a. Que padece abulia, que no tiene voluntad o energía.
b. Que no se puede asir o coger.
c. Coronilla afeitada de quienes entraban a formar parte de la clerecía.
d. Presentimiento, presagio de algo que va a suceder.
e. Astilla o palo de madera impregnados en resina y que, encendidos, sirven para alumbrar o prender fuego. 
f. Pronunciar un discurso solemne y de tono elevado pronunciado ante una multitud con el fin de enardecer los ánimos.

g. Imagen obtenida por daguerrotipia, procedimiento fotográfico químico que fija en una placa de plata la imagen obtenida en una cámara oscura.

h. Bebida de ingredientes desagradables y mal aspecto.

i. Cortar la garganta o el cuello de una persona o animal.

j. Armazón que se ponían las mujeres bajo la falda para que abultasen los vestidos por detrás.

k. Paredes blanqueadas con cal, yeso o tierra blanca.

1. Cintura del cuerpo humano.

m. Tejido hecho con urdimbre de crin de caballo.

n. Herraje articulado o bisagra metálica que fija las hojas de una puerta o ventana y permite que se abatan.

o. Hoja delgada de pan ácimo y de forma circular de que están hechas las hostias sagradas.

p. Sin carne, demacrado.

q. Quitar el pellejo del cuerpo o de alguno de los miembros de un animal.

6. COMPLETAR ORACIONES. Completa las oraciones siguientes con la palabra apropiada del ejercicio anterior.

Haz los cambios que creas necesarios:

a. En los bailes que salen en las películas del siglo XVIII las mujeres llevaban para que sus largos vestidos se vieran más bonitos.

b. El niño lloraba cada vez que le daban la medicina. Decía que era un repugnante.

c. El carnicero los conejos que había recibido para venderlos.

d. En Andalucía es típico ver pueblos enteros de color blanco, con las paredes el mejor sistema para reflejar el sol.

e. Los del portón del edificio chirriaban mucho y tuvieron que echarles aceite.

f. Cuando se perdieron en la isla, improvisaron unas se refugiaron. de madera de pino para entrar a la cueva donde

g. El chal que llevaba la reina en la ceremonia oficial estaba hecho de

h. Los musulmanes suelen varios carneros para celebrar la fiesta del cordero.

i. Desde que le dejó su novia se ha vuelto un nadie.

j. Los monjes del monasterio que visitamos en Ávila llevaban la coronilla

k. El museo conserva muchos del tiempo en que se fundó la ciudad.

1. La novia iba muy guapa el día de su boda. El cinturón del vestido marcaba su cho.

m. Carlos tuvo la de que le tocaría la lotería y al mes siguiente era rico, le tocó el premio gordo.

n. La última vez que fui a misa, se me pegó al paladar la de la hostia sagrada.

o. Los niños lo pasaron muy bien intentando atrapar las pompas de jabón que hacía el payaso.

p. El general a los soldados antes de la batalla con el fin de infundirles valor.

q. La modelo adelgazó tanto por su profesión que tenía el aspecto de los anoréxicos.

\section{SOLUCIONES}

\section{SOLUCIÓN DE LA ACTIVIDAD 1 AMERICANISMOS:}

a. Camión / Autobús b. Bolsa / Bolsillo de las prendas de vestir c. Expendio / Tienda pequeña donde se vende al por menor d. Sinfonola / Máquina tocadiscos que funciona con monedas e. Manija / Asa, parte por la que se agarra un objeto f. Tapete / Alfombra pequeña g. Veladora / Lamparilla que consta de una vasija de aceite o parafina y una mecha h. Recámara / Habitación, alcoba o aposento i. Tina / Bañera j. Saco / Chaqueta, americana k. Platón / Recipiente de gran tamaño, fuente l. Escarapelado / Desconchado. Pared que ha perdido su enlucido 


\section{SOLUCIÓN DE LA ACTIVIDAD 2 EXPRESIONES:}

a. Tomar la delantera: Adelantarse, aventajarse o anticiparse a alguien.

b. Ir al grano: En cualquier asunto, ir derecho a lo principal o fundamental sin entretenerse en rodeos.

c. (A) ras de suelo: Casi tocando, casi al nivel del suelo.

d. Con cautela: Precaución, reserva con que se hace algo.

e. Caminar de puntas: Andar pisando con la punta de los pies (España: de puntillas).

f. A gatas: Modo de estar o desplazarse apoyando los pies y las manos en el suelo.

g. A tientas: Guiándose con el tacto al moverse en la oscuridad.

h. De cuclillas: Apoyando las nalgas en los talones.

\section{SOLUCIÓN DE LA ACTIVIDAD 3 LÉXICO I (de la página 1 a la 15):}

1. k 2. h 3. i 4. j 5. p 6. e 7. c 8. 19. m 10. o 11. a 12. d 13. b 14. f 15. q 16. g 17. n

\section{SOLUCIÓN DE LA ACTIVIDAD 4 COMPLETAR ORACIONES:}

a. emaciado b. tafetán c. cofia d. quinqué e. aguamanil f. canonjía g. zaguán h. migajas i. listón j. fofos $\mathbf{k}$. erisipela l. inconclusa $\mathbf{m}$. arcón $\mathbf{n}$. remedar $\mathbf{o}$. tragaluz $\mathbf{p}$. iconografía q. limo

\section{SOLUCIÓN DE LA ACTIVIDAD 5 LÉXICO II (de la página 16 a la 30):}

1. k 2. m 3. i 4. q 5. a 6. p 7. c 8. 19. o 10. b 11. d 12. n 13. f 14. h 15. j 16. g 17. e

\section{SOLUCIÓN DE LA ACTIVIDAD 6 COMPLETAR ORACIONES:}

a. polisón b. brebaje c. despellejó d. enjalbegadas e. goznes f. teas g. crinolina h. degollar i. abúlico j. tonsurada k. daguerrotipos l. talle $\mathbf{m}$. premonición $\mathbf{n}$. oblea $\mathbf{~ o . ~ i n a s i b l e s ~} \mathbf{p}$. arengó q. descarnado

\section{ANEXO IV:}

\section{ACTIVIDADES DE COMPRESIÓN E INTERPRETACIÓN DE LA LECTURA}

A) Después de leer Aura, responde a las siguientes preguntas de compresión e interpretación de la lectura. Recuerda que en la mayoría de los casos no encontrarás la información en el texto, sino que tendrás que dar tu propia interpretación de los hechos, intentando razonar tus respuestas:

1. El comienzo de la obra dice así: "El hombre caza y lucha. La mujer intriga y sueña; es la madre de la fantasía, de los dioses. Posee la segunda visión, las alas que le permiten volar hacia el infinito del deseo y de la imaginación... Los dioses son como los hombres: nacen y mueren sobre el pecho de una mujer..." Jules Michelet (Historiador francés, 1798-1874) Teniendo en cuenta la lectura de Aura, ¿podrías explicar las palabras de Jules Michelet? ¿Estás de acuerdo con él? ¿Por qué sí/no?

2. ¿Por qué crees que el personaje que representa la encarnación de la Señora Consuelo se llama Aura? ¿Puedes encontrar una relación entre el nombre y el personaje?

3. ¿Cómo interpretas el hecho de que la Señora Consuelo se encuentre siempre a oscuras? Recuerda que menos el cuarto de Felipe, la casa entera se encuentra en penumbra en todo momento.

4. ¿Qué relación existe entre el conejo y Aura a lo largo de la historia?

5. ¿Y entre la señora Consuelo y Aura? Intenta explicarlo.

6. ¿Por qué hay siempre migajas de pan sobre la colcha de la cama de la Señora Consuelo?

7. Felipe dice en varias ocasiones en el texto que sigue a Aura con el oído, no con la vista, solamente oyendo el susurro de su falda de tafeta (pág.7) y ésta aparece siempre de forma "imprevista, sin ningún ruido" (pág.7) ¿Por qué crees que Aura no hace nunca ruido al moverse o al andar?

8. El color verde es recurrente en la narración. ¿Qué cosas encuentras de color verde en el texto?, ¿Con qué relacionas el color verde?, ¿Encuentras alguna conexión entre el significado del color y dichos objetos? 
9. En el texto aparecen numerosos elementos (objetos, animales, etc.) y ritos relacionados con la brujería y la magia negra. ¿Puedes encontrarlos?

10. En la página 21 Felipe enumera las plantas que descubre en el jardín de la casa, y en la número 27 , en los papeles del general Llorente, dice que "Las hierbas no la fertilizarán en el cuerpo, pero sí en el alma..." refiriéndose a Consuelo. Lee atentamente la descripción de las plantas del jardín e intenta explicar la relación existente entre éstas, lo que dice el general sobre su mujer en la página 27 y el estado hipnótico en que se halla Aura permanentemente en la novela.

B) Ahora reúnete con un grupo de compañeros, haced una puesta en común sobre vuestras respuestas a las preguntas anteriores e intentad llegar a un acuerdo sobre la interpretación más factible de las mismas.

C) Después de esto, exponed a la clase vuestras conclusiones y debatid sobre vuestros puntos de vista con el resto de la clase.

D) Finalmente, dad vuestra opinión sobre la novela que habéis leído: ¿Qué os ha parecido? ¿Os ha gustado? ¿Por qué sí/no?

ANEXO V9:

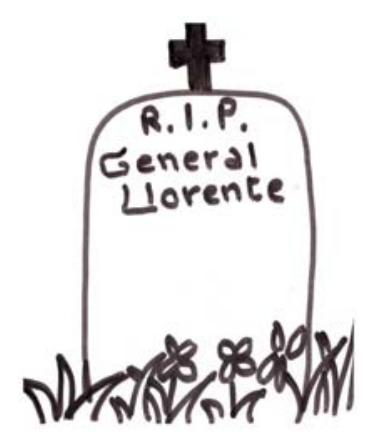

ANEXO VI:

\section{EL PERRO}

“Tocas en vano con esa manija, esa cabeza de perro en cobre, gastada, sin relieves: semejante a la cabeza de un feto canino en los museos naturales. Imaginas que el perro te sonríe y sueltas su contacto helado. La puerta cede al empuje levísimo, de tus dedos...”

No resultaría interesante señalar al perro como un animal simbólico en el texto si no fuera porque se nombra en el mismo párrafo tres veces, y porque además, es el que custodia la puerta (simbólicamente). Si analizamos el ejemplo notaremos que el perro es comparado a un feto (signo que tiene que ver con lo que se gesta en un vientre) y además parece que le sonríe como si le estuviese dando la bienvenida al personaje. El perro, la manija de la puerta, conduce a la casa de Aura. Este perro de bronce se sitúa en un lugar de transición entre dos espacios: el afuera, la ciudad, y el adentro, la casa. Es conocido que simbólicamente el perro cumple la función de mediador entre el mundo de los muertos y el de los vivos. En muchas culturas, y sobre todo en la nuestra, la occidental, está relacionado con la muerte y actúa como guía de las ánimas, de los muertos. Anubis, Cerbero, son algunos de los nombres con los cuales se le reconoce. Este aspecto simbólico que relaciona al perro con un mundo de magia y esoterismo es el que interesa resaltar, porque Felipe Montero, al franquear esta puerta, cuya custodia simbólica es un perro, ha dejado atrás el mundo concreto del que proviene para penetrar al mundo de Aura, mundo mágico y abstracto. Recordemos que toda transición implica en cierta forma un cambio de estado, un dejar atrás un estado anterior para vislumbrar uno nuevo ya sea físico o de conciencia.

\section{LOS GATOS}

Signo contradictorio en el texto porque son objeto de odio y maltrato, pero también de amor, incluso de prácticas perversas que son equiparadas a rituales de sacrificio que se justifican en el amor.

“J’ ai même superté ta haine des chats, moi qu’aimais tellement les jolies bêtes... Un día la encontró, abierta de piernas, con la crinolina levantada por delante, martirizando a un gato y no supo llamarle la atención porque le pareció que tu faisais ça d' une façon si innocent, par pur enfantillage e incluso lo excitó el hecho, de manera que esa noche la amó, si das crédito a tu lectura, con una pasión hiperbólica, parece que tu 
mávais dit que torturer les chats était ta manière a toi de rendre notre amour favorable, par un sacrifice symbolique..."

Consuelo los odia y el General Llorente los ama.

El gato es un símbolo ambiguo, por un lado, en su sentido más positivo, es el protector de la casa, de la madre y la progenie, sin embargo, también son asociados a las brujas, al diablo y a la hechicería.

¿Por qué tanto odio a los felinos por parte de Doña Consuelo? Quizás porque representan la imposibilidad de la maternidad y el amor desmedido que su esposo profesaba a esos animales (debe recordarse que el General Llorente no pudo darle hijos a Doña Consuelo), o quizás también los odia porque, junto con otros ritos que más tarde realiza esta mujer, son portadores de la esperanza de la fertilización. Otra obsesión que se desarrolla en la historia por parte de este personaje femenino y que la asocia directamente a la hechicería y la magia.

\section{EL MACHO CABRÍO}

El macho cabrío es un animal trágico (la palabra tragedia significa literalmente canto del buco). La tragedia es en su origen un canto religioso con que se acompaña del sacrificio del macho cabrío. No olvidemos que el sacrificio de una víctima implica todo un proceso de identificación. El macho cabrío de esta historia representa el mundo de la masculinidad que se degüella.

"La encuentras en la cocina, sí, en el momento en que degüella un macho cabrío: el vapor que surge del cuello abierto, el olor a sangre derramada, los ojos duros y abiertos del animal te dan náuseas: detrás de esa imagen, se pierde la de una Aura mal vestida, con el pelo revuelto, manchada de sangre, que te mira sin reconocerte, que continúa su labor de carnicero".

Este acto es repudiado por el personaje masculino y hace que vea a Aura desprovista de toda la belleza y la fragilidad que él ha apreciado en otras ocasiones, y lo obliga a retirarse, refugiarse en su cuarto, como si de manera implícita este acto sangriento lo identificara con el macho cabrío.

"Subes a tu recámara, entras, te arrojas contra la puerta como si temieras que alguien te siguiera: jadeante, sudoroso, presa de la impotencia de tu espina helada, de tu certeza: si algo o alguien entrara, no podrías resistir, te alejarías de la puerta, lo dejarías hacer...”

Por último, en relación a este animal, debemos anotar que el macho cabrío está también, como el conejo, relacionado y consagrado a Afrodita en cuanto a animal de naturaleza ardiente y prolífica. En conclusión, santo y divino para unos, satánico para otros, el cabro es efectivamente el animal trágico que simboliza la fuerza del impulso vital, a la vez generoso y fácilmente corruptible.

Lo que llama la atención en casi todos estos animales simbólicos es su relación con la fertilidad, con la vida y la juventud, destacándose una vez más esta necesidad de no envejecer, de no dejar de ser útil, como si con ello se dejara de existir. Y por otra parte la reiterativa insistencia de fertilizar, de exaltar las capacidades reproductoras y sexuales de los personajes implicados en la narración.

(buco: macho cabrío)

\section{EL CONEJO}

Las liebres y los conejos están vinculados a la vieja divinidad de la Tierra Madre, al simbolismo de las aguas fecundantes y regeneradoras. También se dice que son lunares porque duermen de día y brincan de noche, porque saben, a semejanza de la luna, aparecer y desaparecer con el silencio y la eficacia de las sombras. El conejo que aparece en la obra es un ser de oscuridad y sombra que sólo se le ve cuando está con Doña Consuelo en la cama comiendo migajas.

El conejo también es el principio de la renovación cíclica de la vida, gobierna en la tierra la continuidad de las especies vegetales, animales y humanas. Es curiosa la asociación de este animal simbólico y ese deseo constante y sistematizado de conservación y renovación de la antigua vida de los personajes en la obra. Además, por si fuera poco, el conejo, que en realidad es coneja, se llama Saga. Saga, como sabemos, implica una continuidad, un seguimiento de la historia de un clan, de una familia, de un hecho. Significativo este signo que se une al resto de los signos relacionados con esta misma problemática de la preservación y renovación del ser.

Mas no es todo, la narrativa nos propone además una analogía entre Aura y la coneja Saga, que refuerza las características simbólicas del animal y las traslada a la figura de Aura. Recordemos el pasaje donde Felipe Montero está hablando por primera vez con la Señora Consuelo y repentinamente grita:

“- Saga. Saga. ¿Dónde estás? Ici, Saga... 


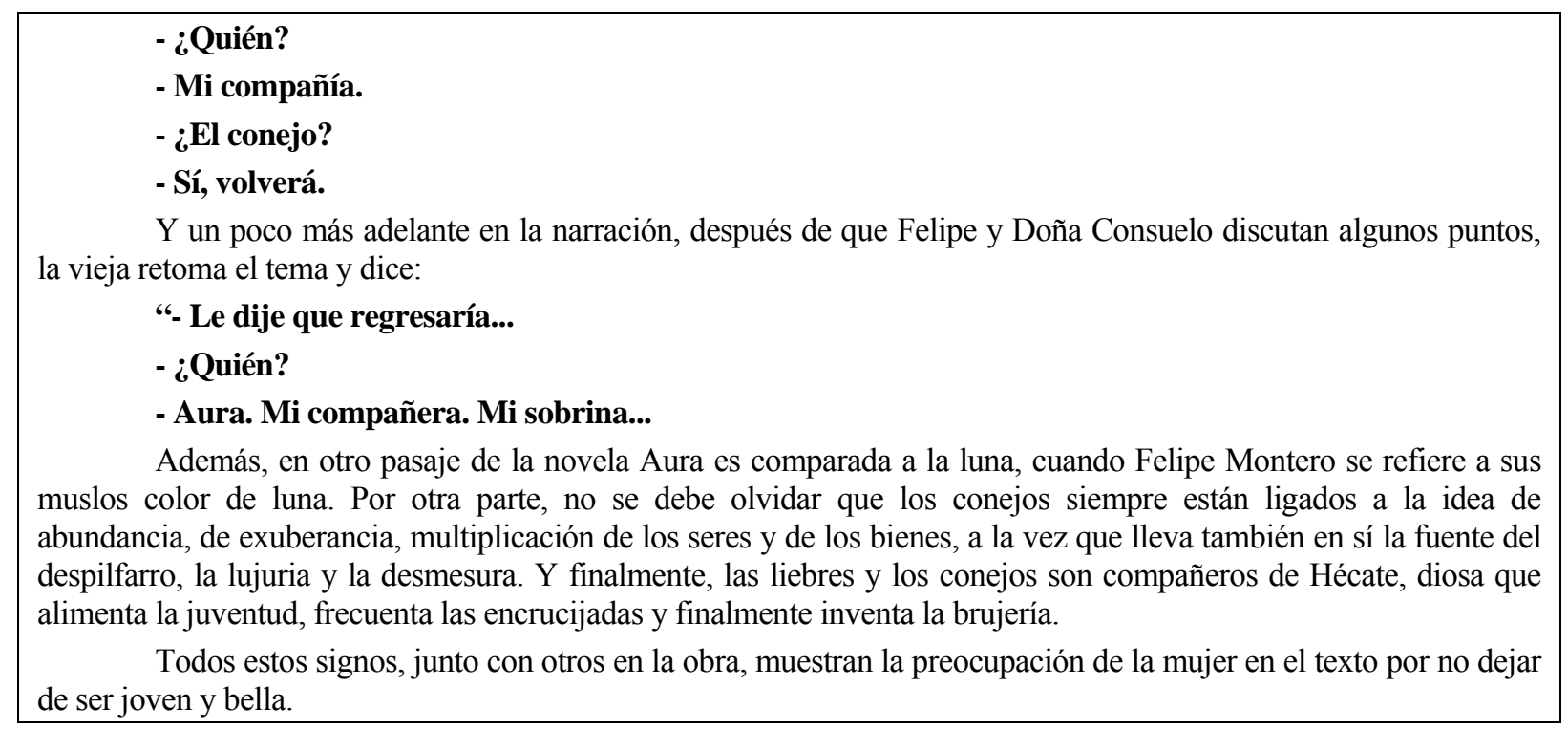

\section{ANEXO VII:}

\section{FICHAS DEL TRIVIAL DE NOVELA}

1. ¿Qué hay en la manija/asa de la puerta de la casa de la Señora Consuelo?

2. ¿De qué color son las cintas que atan los 3 folios de las memorias del general Llorente?

3. ¿Cuántos años hace que murió el general Llorente?

4. ¿Qué significa el nombre de la coneja, "Saga"?

5. ¿Cómo es el techo de la habitación de Felipe?

6. ¿En qué idioma están escritas las memorias del general Llorente?

7. Según los cálculos de Felipe, ¿Cuántos años tiene la señora Consuelo en la actualidad?

8. ¿De qué color son los ojos de la señora consuelo?

9. ¿De qué alimentos se compone la dieta preferida de la casa?

10. ¿Qué edad tenía el general Llorente cuando murió?

11. ¿Qué son las migajas de la cama de la señora Consuelo?

12. ¿De qué color viste siempre Aura?

13. ¿Qué abre el llavín que le da Felipe a Aura? 


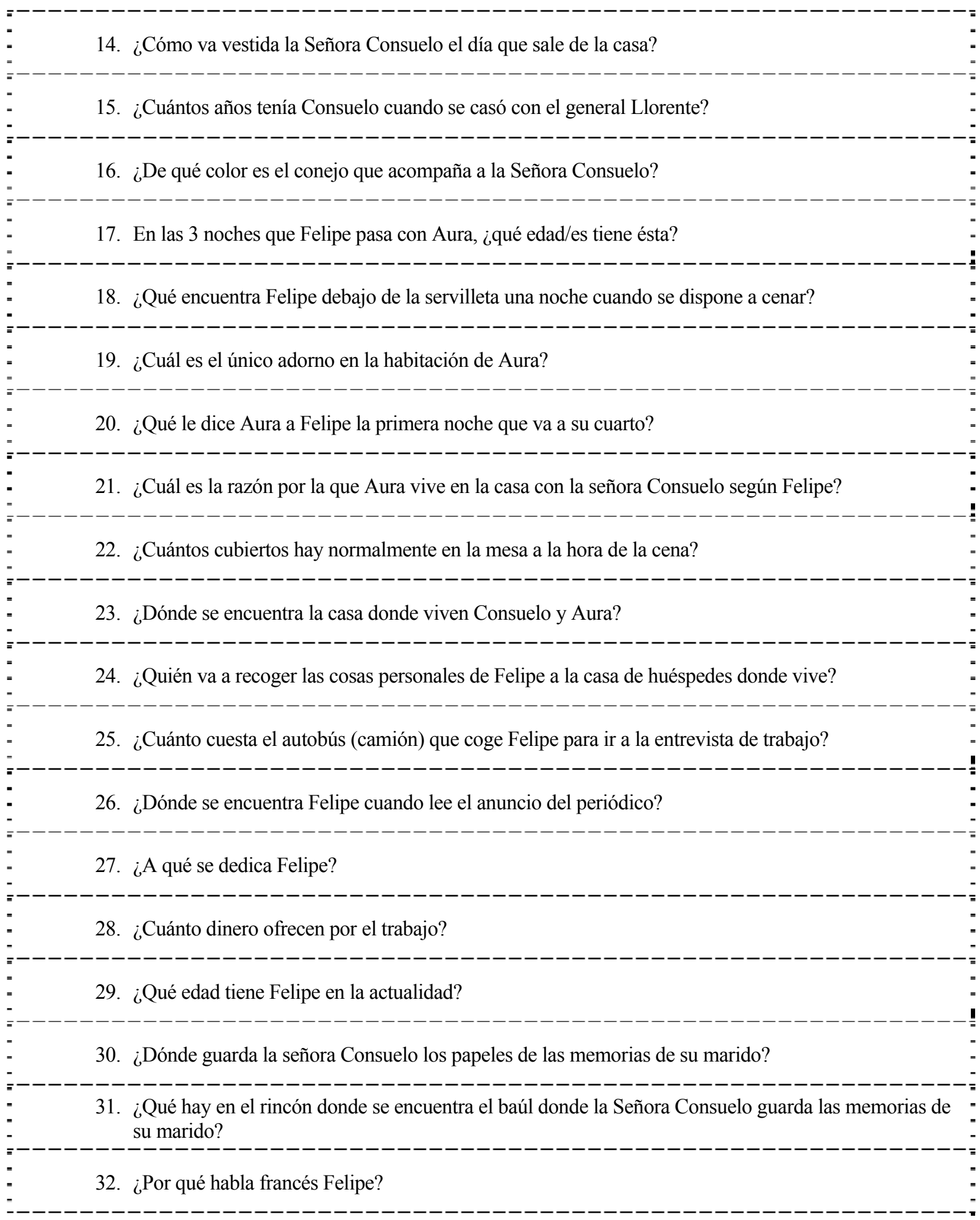

\section{SOLUCIONES DEL TRIVIAL DE NOVELA}

1. Una cabeza de perro (pág. 3) 2. Amarilla, azul y roja (págs. 12/17/27) 3. 60 años (pág. 5) 4. Sabia (pág. 18) 5. Es un tragaluz (pág. 8) 6. En francés (pág. 12) 7. 109 años (pág. 19) 8. Amarillos (págs. 6/15) 9. Riñones, tomates y vino (págs. 9/15) 10. 82 años (pág. 15) 11. Costras de pan/de oblea (págs. 5/11/22) 12. De verde (págs. 9/16/22/25) 13. Un cajón de la mesa donde guarda sus documentos (pág. 10) 14. Con un traje de novia amarillento (pág. 26) 15. 15 años (pág. 18) 16. Blanco (pág. 17) 17. 20, 40 y 109 respectivamente (págs. 22/19) 18. Una muñeca de trapo (pág. 20$) 19$. Un Cristo negro (págs. 16/22/23) 20. "Eres mi esposo" (pág. 17) 21. "Para perpetuar la ilusión de juventud y belleza 
de la pobre anciana enloquecida" (pág. 19) 22. Cuatro (págs. 9/15) 23. En el viejo centro de la ciudad/En la calle de Donceles (pág. 2) 24. El criado (pág. 9/24) 25. 30 centavos (pág. 2) 26. En un cafetín sucio y barato (pág. 2) 27. Es historiador (pag. 2) 28. Primero 3.000 pesos, después 4.000 pesos (pág. 2) 29. 27 años (pág. 28) 30. En un arcón (pág. 12/17) 31. Un nido de ratones/Ratas (págs. 12/17/26/27) 32. Porque fue estudiante/becario en la Sorbona (pág. 2)

\section{ANEXO VIII:}

\section{SISTEMA DE PUNTUACIÓN DEL TRIVIAL DE NOVELA}

- El equipo A tomará una decisión sobre la respuesta a la pregunta planteada.

- Si la respuesta es correcta, el equipo A recibe 2 puntos.

- Si no sabe la respuesta, el equipo contrario responderá a la pregunta. Si es correcta, el equipo B recibe 2 puntos.

- Si la respuesta es incorrecta o no la sabe, el equipo A tendrá opción a buscar la respuesta en el texto. Si es correcta, recibe 1 punto. Si no lo es, pasa de nuevo el turno al equipo B y recibe 0 puntos.

- El equipo B buscará la respuesta en el texto, y si es correcta recibe 0.5 puntos. Si no lo es, recibe 0 puntos.

- El juego continuará de la misma forma. Esta vez el equipo B levantará una ficha y así sucesivamente.

\section{ANEXO IX:}

FICHAS DE ESCULPIR

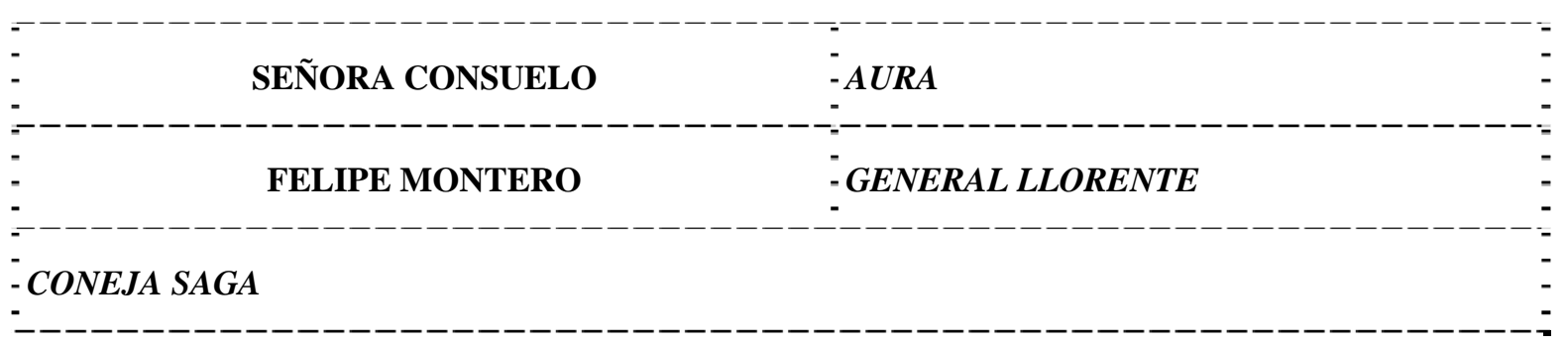

\section{INSTRUCCIONES}

Señora Consuelo: En el centro, con una cofia en la cabeza que le cubre las orejas, está sentada como si estuviera en una cama, tapada por sábanas y edredones, sólo los brazos están fuera de ellos. Tiene la mano izquierda sobre el vientre y la derecha extendida al lado del cuerpo. Los ojos están desmesuradamente abiertos mirando al vacío y los labios cerrados, inmóviles. (En la cama casi siempre, a oscuras, rodeada de velas y objetos religiosos. Su objetivo es dar vida una y otra vez a su "sobrina" Aura, que es la reencarnación de su juventud).

Aura: A su izquierda, de pie junto a la cama de la señora Consuelo, con la mano derecha sosteniendo la campana, con el velo verde puesto sobre la cabeza y el brazo derecho caído sin fuerza. La mirada fija en un punto inconcreto en el aire, inmóvil, como si fuera un robot. (Siempre en actitud de trance, robótica, repite los gestos de la señora Consuelo, aparece y desaparece a voluntad de ésta y se mueve sin hacer ruido, como en un sueño. Va envejeciendo conforme transcurre la historia hasta desaparecer).

Felipe Montero: A su derecha, mirando incrédulo con la boca abierta a la Señora Consuelo, como hipnotizado. En sus manos sujeta un trozo de papel con el anuncio del periódico y tiene los brazos un poco extendidos hacia la señora Consuelo, como enseñándoselo. (Historiador joven y con pocos recursos que tras leer un anuncio en el periódico acude a casa de la señora Consuelo para terminar las memorias de su marido muerto, el general Llorente). 
General Llorente: Sentado en un escritorio escribiendo sus memorias sobre un papel y rodeados de otros muchos papeles. Con su mano derecha escribe y su cabeza está mirando un poco hacia arriba, en actitud pensativa, como recordando su pasado junto a Aura. (General mexicano que vivió buena parte de la historia del México del siglo XIX y exiliado finalmente en Paris. Deja sus memorias inconclusas en las que narra su pasado militar y su vida junto a la bella y enigmática Aura).

Coneja Saga: A los pies de la cama de la señora Consuelo, con sus patas sujetando algo como un trozo de pan y con la cabeza gacha, como royéndolo. (Siempre junto a la señora Consuelo, aparece cuando no está Aura y desaparece cuando ésta hace acto de presencia, como si las dos estuvieran conectadas o fueran el mismo ser).

\title{
ANEXO X:
}

1. ¿Sabéis lo que es un bolero? ¿Conocéis alguno? Consultad con vuestros compañeros o buscad en internet. Después contadlo a la clase.

2. Vais a escuchar y visionar un bolero muy conocido interpretado por el tenor español Plácido Domingo. Antes de escuchar la canción, en grupos de 3, intentad completar la letra de la canción, teniendo en cuenta el sentido de los versos. En caso de incluir formas verbales, intentad utilizar el tiempo verbal más adecuado.

\author{
Aquellos ojos verdes \\ Aquellos ojos verdes \\ de mirada \\ dejaron en mi alma \\ eterna sed de \\ Anhelos de \\ de besos y ternuras \\ de todas las dulzuras \\ que sabían \\ Aquellos ojos verdes \\ serenos como un \\ en cuyas quietas aguas \\ un día me \\ No saben las \\ que en mi alma han dejado \\ aquellos ojos verdes \\ que yo nunca \\ (Se repiten las 3 últimas estrofas)
}

3. Ahora vais a escuchar la canción, prestando atención a las palabras que faltan y que habéis completado anteriormente.

(SOLUCIÓN: serena / amar / caricias / brindar / lago / miré / tristezas / olvidaré)

4. ¿Habéis acertado en vuestras hipótesis? ¿Cuántas? Poned en común vuestros resultados con el resto de la clase y comprobad qué equipo se ha acercado más al original.

5. ¿Encontráis alguna relación entre la canción y la historia que habéis leído? ¿Y diferencias?

\section{ANEXO XI:}

\section{DIFERENCIAS EN EL CORTOMETRAJE DE PERRO NOBLE}

1. No hay escena en la cafetería cuando Felipe lee el anuncio del periódico.

2. No hay jardín o patio y hay mucha luz en la entrada de la casa de la señora Consuelo.

3. No hay manija de perro en la puerta de la casa. 
4. El protagonista se llama Felipe Olivera y es profesor en la Facultad.

5. La señora Consuelo va vestida de novia desde el principio.

6. El marido de la señora Consuelo se llamaba Patricio Franco y era Licenciado.

7. El marido de la señora Consuelo murió hace 30 años, no 60.

8. No hay coneja Saga.

9. Los ojos de Aura no son verdes, su pelo es castaño y el vestido es negro.

10. La cena no es de riñones, vino tinto y tomates asados. En la primera cena hay sopa y en la segunda espaguetis. En ambas beben algo que parece vino blanco.

11. Sólo hay un paquete de documentos de las memorias del marido de la señora Consuelo.

12. Las memorias están escritas en español, no en francés.

13. No hay ratas en el rincón donde se encuentra el arcón de las memorias.

14. No hay escena de los gatos encadenados en el patio.

15. La habitación de Felipe no tiene tragaluz, sino una gran cristalera.

16. Felipe usa un ordenador.

17. Sólo hay una escena de los encuentros amorosos entre Felipe y Aura, por lo que Aura tampoco va envejeciendo.

18. Felipe no encuentra una muñeca de trapo debajo de la servilleta en la cena.

19. Aura aparece dando hachazos a un cerdo, no a un macho cabrío.

20. No hay escena de la misa sacrílega en los muslos de Aura.

21. El final es diferente en varios aspectos, pero no en lo esencial.

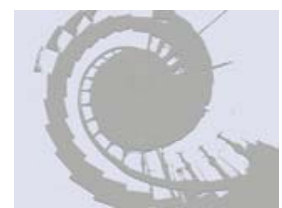

${ }^{1}$ Todas las referencias futuras a las páginas del libro Aura, corresponden a esta edición: Fuentes, Carlos. Cuentos sobrenaturales. Madrid: Alfaguara, 2007.

${ }^{2}$ Esta suele ser la duración aproximada de un curso regular en los centros del Instituto Cervantes.

${ }^{3}$ Es conveniente hacer etiquetas con el nombre de los cuatro animales. Habría que situar una sobre la mesa de cada equipo y distribuir el resto a los alumnos para que las utilicen como identificación personal, facilitando así la tarea del profesor y evitando confusiones al llevar a cabo la actividad.

${ }^{4}$ La información sobre el significado simbólico de los animales en la novela está sacada del estudio realizado por Cecilia Eudave (2001), con ligeras modificaciones para su uso en esta actividad.

${ }^{5}$ En el Anexo IX damos un ejemplo de cómo podrían ser las instrucciones para formar la escultura, aunque en la práctica sería el alumno elegido como escultor el que las daría.

${ }^{6} \mathrm{Si}$ se encuentra, existe un cortometraje animado titulado "Los ojos del deseo" de Yazmín Sánchez y Humberto Garrido. En Youtube solamente se puede ver un tráiler del mismo, pero merecería la pena visionarlo por completo, pues muestra ser de alta calidad.

${ }^{7}$ También hay una lectura completa de la novela por Carlos Fuentes en Youtube (Aura (en la voz de su autor) Duración: 1.27'). El profesor puede informar de esto a sus alumnos para que lo escuchen en casa si lo desean o utilizar el material auditivo para llevar a cabo cualquier otra actividad en el aula.

${ }^{8}$ Una propuesta muy interesante y provechosa para trabajar el léxico de un texto literario de forma significativa cuando tratemos con textos breves o fragmentos de obras literarias la encontramos en un artículo de Ventura Salazar (2012: 176-179), donde el vocabulario elegido para trabajar su significado vuelve a insertarse en el texto original de donde procede (la actividad se centra en los adjetivos, pero podría llevarse a cabo también con sustantivos).

${ }^{9}$ Este diseño de lápida (sin nombre) aparece en el libro de Collie y Slater (2002). Lo que presentamos es una adaptación de la actividad a la novela y el personaje del General Llorente. 